\title{
REGIMEN JURIDICO DE LA CONSTRUCCIÓN \\ DE OBRA PÚBLICA EN CHILE HASTA \\ EL SIGLO XVIII \\ (Notas para su estudio)
}

\author{
Maria Angélica Ficueroa Quinteros \\ Profesora de Historia del Derecho
}

J. Introducción. 2. Algunos planteamientos generales sobre el tema.

3. Ia legislación. 4. La calidad de obra pública y sus privilegios: a) financiamiento privilegiado; b) privilegios relativos a la mano de obra; repartimiento de trabajo, trabajo de presidiarios; c) expropiación y comiso o requisición de materiales y de transporte. 5. Sistema de financiamiento: propios, derramas y sisas. 6. Régimen de ejecución de obras públicas.

\section{I N TR O D U C G $16 \mathrm{~N}$}

E) propósito de esta comunicación es dar a conocer parte de una investigación cuyo objetivo inicial consistió en determinar el régimen juridico que reguló la construcción de algunas obras públicas realizadas en Chile en el siglo xvir. Sin embargo, el desconocimiento del estatuto jurídico modelado en los dos siglos anteriores, respecto del cual se presentaban permanentes modificaciones, impidió el esclarecimiento de importantes aspectos, llevando necesariamente al estudio, previo del régimen jurídico de los siglos xvr y xvir.

La extensión del tema y el exceso de documentos sobre la materia hacen preciso, de partida, dejar constancia sobre las limitaciones del presente trabajo, no sólo al titularlo con esa espectfica finalidad como notas, sino aún más expresamente, haciendo presente que, referida la

- Ponencia al vi Congreso del Instituto Internacional de Historia del Derecho Indiano, 1980. Valladolid (Espafia). 
investigación sólo a las obras públicas civiles, dentro de éstas únicaménte se ha pretendido estudiar la actividad desarrollada en este campo por el cabildo santiaguino, fundamentalmente a través de sus actas de sesiones. Queda fuera, por tanto, el estudio sistemático de las labores desempeñadas por corregidores y por el gobernador. Tampoco he ahondado en la posible existencia de diferencias entre obras públicas que podríamos llamar reales y comunales en la medida en que dicha diferencia no apareció de manifiesto en los documentos revisados.

En consecuencia, el objetivo del presente trabajo ha sido abordar el estudio del régimen jurídico de la construcción de obras públicas en Chile indiano en relación a la actividad del cabildo sobre la base de ciertos documentos de aplicación del derecho y confrontarlos con la regulación legal sobre la materia.

\section{A L G U N O S P L A N T E A M I E N

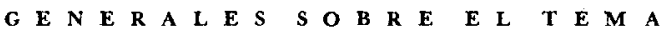

Parecen útiles ciertas consideraciones previas relativas al tema gene. ral del régimen jurídico de las obras públicas en Chile colonial.

Es posible que ninguna actividad dentro de la vasta tarea desplegada por España en Indias presente mayor uniformidad que la acción destinada a crear en América los elementos materiales de utilidad común o de uso público.

Sin embargo, la construcción de obras públicas en la gobernación de Chile aparece con ciertos matices de especial carácter en este lejano territorio de los dominios de la corona castellana. Entre los factores que determinaron dicha singularidad podemos anotar, entre varios otros, las destrucciones periódicas que sufrieron las construccione; públicas chilenas como consecuencia de los repetidos sismos, terremotos e inundaciones característicos de la conformación geológica y geográfica del país. Estos hechos pusieron a prueba los mejores empeños de progreso material, al dejar en calidad de tarea por comenzar, aquello que en otras regiones americanas era un paso avanzado sobre el cual se cimentaban nuevas construcciones, públicas y privadas.

Al hecho mencionado hay que agregar la interminable guerra de Arauco, que también en este aspecto, como en tantos otros, marcó históricamente la fisonomia de Chile, no sỏlo por las destrucciones pe- 
riódicas, como consecuencia directa y física del conflicto, sino también por su efecto de obligado ausentismo de autoridades y vecinos de las zonas pacificadas en el cumplimiento de funciones de defensa durante más de medio siglo. Más adelante, en las centurias siguien. tes, continuará gravitando sostenidamente como factor negativo en la conomía al crear necesidades adicionales en materia de caminos y obras de defensa o estrategia.

No se puede omitir tampoco la casi legendaria pobreza del reino de Chile que, discutible o no en la actualidad, como dato incontrovertido en esa época, fundamentó muchas decisiones de importancia.

En el hecho, tanto la narración escueta de la crónica al igual que el comentario o interpretación de nuestros más diversos historiadores coinciden en mostrar a lo largo de la historia de Chile un permanente empeño por llegar a materializar construcciones de bien público, las que se prolongan excesivamente en el tiempo. Esta situación se manifiesta dentro de un marco general de cierta incapacidad por par. te de la población para soportar el esfuerzo económico que dichas obras significaban, junto a una aparente complejidad burocrática que parece desprenderse de los trámites legales y administrativos que debian cumplirse.

Nuestros archivos contienen nutridos expedientes que dan fe de la frondosa y cuidada documentación que acompañó la construcción de cada obra pública emprendida o proyectada. Preciso es señalar que estos legajos sólo han sido usados en trabajos netamente históri$\cos$ o, en forma adicional, en estudios histórico jurídicos sobre algúm organismo especifico. Están prácticamente intocados los archivos correspondientes a la parte contable de estas obras, en especial los que conforman los fondos de Contaduría Mayor.

Por las razones anotadas se presenta como tema especialmente atractivo el conocimiento deJ derecho aplicado en el reino de Chile en las construcciones de obras públicas. Junto al interés que produ. ce el desconocimiento del tema general aparecen plausibles ciertas hipótesis o posibles diagnósticos en cuya comprobación sería importan. te trabajar. Así, habría que estudiar si existió un entorpecimiento producido en la realidad indiana por la aplicación de una normativa jurídica cuyos fundamentos en el Viejo Mundo distaban bastante de la urgencia y expedición requeridas en América para la creación de toda la infraestructura material. 
De comprobarse la veracidad de tal supuesto, surgiría otra pregunta; ésta consiste en saber si para superar dicha situación se acudió a la creación de derecho por los organismos indianos.

Agrega interés al planteamiento anterior un fenómeno aparentemente paradójico. Me refiero al enorme cambio que se manifiesta en el siglo xvirI chileno tanto en lo que se refiere a la expedición en las realizaciones de obras públicas como en la importancia de ellas; esto se hace especialmente evidente en los períodos de algunose gobernadores de conocida eficacia funcionaria, como es el caso de Ambrosio Higgins. Digo que interesa esta transformación dieciochesca por cuanto ella se presentó superando la persistencia de los factores negativos antes señalados y por lo tanto se concretó en virtud de elementos nuevos que desconocemos.

Aquí se presenta una nueva hipótesis. Pienso que en el siglo xvir pudo producirse una ampliación del concepto de utilidad pública, como consecuencia de la acción de fomento eonómico en que se empeña la corona. Así, se puede apreciar que las Cajas Reales se comprometen con mayor facilidad, mediante aportes o préstamos, en obras de un interés público restringido a ciertos sectores, como es el caso de la minería, la agricultura o el comercio. En esta variación del concepto de utilidad pública pienso que subyace la concepción económica de la ilustración española.

El financiamiento de las construcciones de bien público con cargo a los beneficiarios, principio adoptado en la Recopilación de Indias, se altera al parecer por efecto de la adopción de un postulado económico en que la consideración del beneficio directo es reemplazada por la utilidad común que deriva del progreso económico general que tendrá su mayor manifestación en el desarrollo de la minería, comercio, industria y agricultura.

\section{L A L E G I S L A C 1 C}

La normativa legal propiamente indiana es escasa. Está constituida por unas cuantas leyes incorporadas a la Recopilación de 1680 y por algunas cédulas y reales órdenes posteriores; también hay que agregar la existencia de normas aisladas dentro de cuerpos legales del siglo xviII, como son la Ordenanza de Intendentes de 1782, aplicada en Chile en 1787, en las Ordenanzas de Minas de Nueva España, ex- 
tendidas a Chile a partir de 1787 mediante las Declaraciones de Tomás Alvarez de Acevedo y en las Ordenanzas del Consulado de Chile de 1795. Todas estas últimas normas conforman en torno a la obra pública un sistema vinculado a los planes de fomento económico a que ya he aludido.

Las leyes fundamentales de la Recopilación de Indias están reunidas en el capitulo xvı del libro iv, titulado: "De las obras públicas" y que se compone de sólo cuatro leyes. La primera se refiere al financiamiento de caminos y puentes por los beneficiarios de ellos; Ia segunda establece las autoridades que deben concurrir al acuerdo del Cabildo para decidir sobre la iniciación de una obra pública y la participación en ella de la Audiencia. Las dos últimas leyes del capitulo establecen, la tercera, que un regidor sea superintendente de las obras públicas y la cuarta dispone que las obras públicas realizadas a costa de los Concejos se construyan de tal forma y firmeza que sean de provecho.

Hay otras disposiciones de la Recopilación de Indias que forman parte del régimen jurídico de la obra pública. Me refiero a aquellas que regulan el uso de los propios y rentas de los cabiidos y disponen sobre las derramas, sisas y demás contribuciones, al igual que algunas que tienen por finalidad la organización de los cabildos y aquellas que se refieren a los repartos de trabajo indigena.

Si la normativa legal indiana fue escasa, la supletoriedad de la ley castellana proveyó en cambio de una mayor cantidad de disposiciones, las que se extienden con cierta sistematicidad desde las Partidas llegando en las recopilaciones castellanas del siglo xvI y xix a configurar un régimen de derecho administrativo que regulaba la cons. trucción y mantención de obras públicas.

La legislación mencionada cuenta con amplio aporte de la doctrina, la que aclara los vinculos de dichas normas con el derecho romano y sus comentaristas. El análisis del contenido de estas normas legales y de su complemento doctrinario como punto de contraste con la realidad jurídica debe permitir apreciar el grado de conocimiento y aplicación de estas disposiciones en Chile, problema fundamental en el que se resuelven todos los que plantea el derecho indiano ${ }^{1}$.

${ }^{2}$ Mencionaré las leyes supletorias de los cuerpos legales más importantes: Pattida 2, tic. v, ley $1_{i}$ tit. 20, ley 5 ; Partida 8 , tit. xvur, leyes 16 y 75 ; tit. xxxn, leyes 20 y 21; Partida 5, tit. vil, leyes 10, 16 y 17 . Cito en seguida 


\section{I A C ALI D A D D E O B R A P Ú B L I C A $\begin{array}{llllllllllllllll} & S & \text { U S } & \text { P } & R & I & V & I & L & E & G & I & O & S\end{array}$}

El uso práctico del concepto de obra pública consta desde los inicios del Cabildo de Santiago en numerosos acuerdos. Así, el año 1545, a pocos años de su establecimiento, el organismo capitular acordó construir un puente sobre el río Maipo, geográficamente, el primer obstáculo fluvial de importancia entre la capital y el territorio sur de la gobernación. En la parte que interesa al punto planteado, el documento dice: "por cuanto es bién y provecho de la tierra, de los vecinos y moradores de ella que se haga una puente en el rio Maipo, que todos los vecinos comarcanos que por la dicha puente se han de aprovechar..."2 y continúa estableciendo las bases de financiamiento de la obra. Las expresiones anotadas en el citado documento dan cuenta de la consideración de dos elementos constitutivos de la calidad de pública de una construcción. Me refiero a la utilidad común y al uso público directo.

El procurador síndico de la ciudad precisará aún más el primero de estos conceptos en el acta en que se transcribe el primer contrato destinado a fabricar el puente del Maipo; lo hace en los términos siguientes: "pues esta obra es en pro y utilidad de esta república y beneficio de los naturales y descargo de la conciencia de S. M. y a todos es bién común"3.

Con años de distancia, en 1579, el Cabildo declara que, “por cuanto la puente de Maipo es muy importante y paso común para la gue-

las leyes de la Novísima Recopilación de Castilla, las que por estar concordadas con las respectivas de la Nueva, cuando correspondc. evitan repeticiones. Nov. Rec. Libro vi, título XXII. De los repartimientos de contribuciones entre los vecinos de los pueblos, leyes I a x. Lib. vir, tit. Xxxiv, Obras Públicas, leyes $I$ a $x$. Lib. vII, tit. Xxxv, caminos y puentes, leyes $I$ a $x$. Las citas corresponden a las cdiciones que se señalan y respecto cie la Novísima son muy importantes las notas a las leyes. Las Siete Partidas, glosadas por el licenciado Gregorio López de Tobar, Madrid 1829, 1831, 4 vols. Novisima Recopilación de las Leves de España, edición de Vicente Salvá, París, 1846. 5 vols.

'Actas del Cabildo de Santiago, seción de $26 \mathrm{de}$ agnosto de 1515 , en Co. lección de Historiadores de Chile y documentos relativos a la historia nacional, Santiago de Chile, 1861, 1906; vol. 1, Santiago 1861, 111. En adelante esta colección se citará con la sigla CHCH.

${ }^{3}$ Acta de sesión, 4 de septiembre de 1556, снсн, vol. I, pp. 537 a 540. 
rra y ciudades de arriba..."4, expresiones que contribuyen a aclarar la anotada diferencia entre utilidad común y uso público al hacer expresa referencia al provecho militar de la obra del Maipo que, como elemento de la defensa común, aparece claramente de utilidad general pero cuyo uso o tráfico directo será beneficio concreto sólo de parte de la población.

La importancia de esta distinción parece residir en que el uso para el cual estaba destinada una obra pública fue determinante para establecer el tipo de contribución económica para su financiamiento, en tanto que la utilidad pública o común otorgaba en todo caso a la construcción un conjunto de privilegios, dentro de los cuales basta senalar para demostrar su importancia, la posibilidad de aplicar la expropiación de un terreno para la ejecución material de la obra y la requisición o comiso de materiales y transporte necesarios para ella.

El jurista Jerónimo Castillo de Bovadilla al tratar las obras públicas. en relación a las atribuciones de los corregidores, hace un tratamiento detallado de to que él llama "privilegios o especialidades" anexas a estas construcciones ${ }^{5}$. La legislación en cambio no las considera sistemáticamente, pero ellas se manifiestan en Chile desde el siglo xvi en algunos casos en forma bastante clara en el régimen jurídico aplicado a las obras públicas en que tuvo injerencia el Cabildo.

a) Financiamiento. El más directo de estos beneficios es el financiamiento a través de tres alternativas, con los propios del Cabildo; por la población directamente en forma de derramas, repartimientos o sisas y, en ciertos casos, por la hacienda real. Por ahora dejaremos este punto como simple mención para tratarlo más adelante.

b) Privilegios relativos a la mano de obra. Otro beneficio de que goza uria obra pública es su participación en el repartimiento de tra* bajo.

La Recopilación de Indias, como sabemos, establece el repartimiento de trabajo ${ }^{6}$ para América trasladando la institución desde la Península, como una compulsión al trabajo que recae por igual sobre

Acta de sesión, 9 de octubre de 1579, снсн, vol, 18, Santiago, 1899, 139.

'Castillo de Bovadilia, Jerónimo: Política para corregidores y señores de vasallos, Amberes, 1750, 2 vols. Libro III, cap. v, No 25, 26, 33, 36, 38, 39. 40, 41. Primera edición, Madrid 1597.

'Ley I, tit. XII, Lib. v1. Recopilación de Leyes de Indias, Madrid, Boix editor, 1841 . 
indios, españoles vagabundos y ociosos, mestizos, negros libres y demás castas, mediante contrato con salario tasado. Solórzano, por su parte, precisa la distinción entre reparto de trabajo para las obras públicas propiamente tales y aquel aplicado en beneficio de las actividades mineras, agrícolas y de construcción de particulares, que disfrutan de la calidad de utilidad pública para el efecto de obtener participación en la distribución de la fuerza de trabajo compulsivamente organizada?.

Respecto del trabajo de los indígenas, el mismo jurista comenta que "la intención Real es que se ocupen en todas las cosas que se juzgaren por necesarias a la República: Porque de esto pende la conservación de estas provincias" 8 . Específicamente, tratando del servicio indígena en las obras pública señala que: "se debe guardar y está mandado que se guarden en las Indias...", a ello agrega el testimonio de la aprobación de esta norma por otros comentaristas para finalmente describir "la costumbre de compelerlos a que en ciertos días estén de manifiesto en las plazas $u$ otros lugares públicos, para que de allí los conduzcan y lleven los que necesitan de ellos para estas obras", situación ordenada por la ley de Indias antes citada ${ }^{\mathbf{9}}$.

Se ha dicho que Solórzano no es un comentarista apologético sino un jurista que en sus escritos, y específicamente en su Política Indiana, hace una exposición objetiva del derecho indiano no exenta de críticas razonables ${ }^{10}$, lo que se comprueba respecto del repartimiento de trabajo sobre el cual señala que pese a ser extensivo al español de calidad servil y ocioso, al mestizo, al negro libre y demás castas, aparte del indio, en América se aplicó fundamentalmente sobre éste. Destaco este punto porque caracteriza bastante bien las condiciones del reparto de trabajo para obra pública en Chile en los siglos xvi y xvir sobre el que existen gran cantidad de testimonios.

Recordemos que en Chile el servicio personal en la encomienda no logró suprimirse y si bien repartimiento y encomienda son dos instituciones distintas juridicamente, tratándose del reparto de trabajo

'Solórzano Pereyra, Juan: Politica Indiana, Madrid, 1776, 2 vols., Lib. II, caps. 8 y 9.

Solórzano, ob. cit. lib. n, cap. Ix, No 3.

Solórzano, ob. cit. lib. LI, cap. vIII, No 5.

${ }^{10}$ García Gallo, Alfonso: La Universidad de Salamanca en la formación del derecho indiano. Actas, III Congreso Ins. Int. de H. del Derecho, Madrid, 1973, 97. 
indigena en la práctica del derecho, la confusión es frecuente y más fácil en la situación chilena de permanencia del servicio personai encomendado.

En 1545, en la decisión inicial del Cabildo para construir el puente del Maipo, se establece que "todos los vecinos comarcanos que por la dicha puente se han de aprovechar... sean compelidos y apremiados a que den indios...11. Esta situación, como la generalidad de aquellas pertenecientes a la etapa de conquista, no es muy clara, pues el aporte de trabajo indigena podría ser, no un repartimiento de trabajo, sino una forma especial de pagar la derrama echada sobre los vecinos, pues se agrega que éstos serán compelidos también a dar madera y "todo lo demás necesario". Queda en pie la posibilidad de que se trate de reparto de trabajo, pues más adelante en otros documentos en que aparecen expresiones similares a la anotada, se menciona la tasación del jornal indígena, a menos que sólo se haga para efectos contables del pago de la derrama.

Ya en ejecución la obra del río Maipo se presenta al Cabildo una solicitud para que dispusiera el envío de $\mathbf{4 0}$ indios por una semana para el trabajo del puente. Esta petición fue provelda favorablemente, mandando se repartiera entre los vecinos de la ciudad ${ }^{12}$.

En la obra de la iglesia matriz de Santiago, para cuya ejecución el gobernador dio amplia comisión al Cabildo con el fin de dar cumplimiento a la Real Cédula fechada en 8 de agosto de 155813, correspondió a los indios del obispado un tercio del costo de la obra pues, según disposición de la citada cédula, debía repartirse su financiamiento por terceras partes, debiendo aportar otro tercio la Real Hacienda y el último tenia que pagarse por los vecinos moradores y en. comenderos "atento a la calidad de sus personas y haciendas". En 1583, para llevar a la práctica la decisión real acordó que habiéndor. echado varias derramas de dinero, "conviene que se acabe de cobrar los dichos repartimientos de los indios"14. Se trata en este caso de una derrama que incluyó a los indios, pese a que la tendencia de la

यActa dé sesión, 26 de agosto de 1545, Снсн, vol. 1, 111.

1sActz de sesión, 25 de enero de 1557, снсH, vol. I, 564.

El texto está transcrito en el acta de 6 de diciembre de 1583, chch, vol. 19pp. 164; vol. 19, editado en Santiago, 1889.

${ }^{10}$ Igual. 
legislación ${ }^{15}$ es que los indigenas no entren en los repartimientos de dinero si son innecesarios o excusables.

Para la construcción de un puente en el potrero de la ciudad cuyo objetivo era hacer expedito el tránsito a las salinas, el Cabildo santiaguino encargó su construcción a Francisco de Orense, "para que con los indios comarcanos la haga hacer...; se agregó que "Para tomar los indios necesarios, el Teniente General le dará el mandamiento en forma"16. Aparece en este documento por primera vez de manera expresa el trámite formal de contar con mandamiento del Gobernador para hacer efectivo el repartimiento de trabajo indígena; en adelante será frecuente.

El año 1607 se decidió iniciar la construcción del puente sobre el río Aconcagua y se encargó el control de la ejecución al corregidor del partido de Aconcagua, Curimón y Apalta, capitán Alvaro Rodriguez. Sobre el trabajo indígena, el acta de sesión del Cabildo expresa que haga la obra "con los indios de aquel partido"... "y para cla. vazón y herramienta se echa repartimiento para todos los vecinos de Cuyo atento, que son los que más gozan del beneficio de la dicha puente"17. Aqui nuevamente el trabajo indígena en una obra pública probablemente constituye servicio personal para el pago de una derrama que incluyó a los naturales y que consistió en dinero para materiales respecto del resto de los contribuyentes.

Para la ejecución del puente provisorio en el río Maipo, contratado el año 1616 con el capitán Pedro de Miranda, en un sistema mixto de construcción, el Cabildo aportó doce indios, "pagándoles la ciudad sus jornales"18, situación en que aparece claro que los naturales participan en la construcción en forma de repartimiento de trabajo.

Se comprueba, finalmente sin lugar a dudas, la inclusión de los indígenas en el sistema de derramas para cuyo pago prestarían servicios, en el proyecto de acuerdo presentado en cabildo abierto el año 1616, en que el Ayuntamiento pretendió imponer una sisa en beneficio de las obras públicas y estableció que las "comunidades de in-

\footnotetext{
${ }^{15}$ Rec. Ind. ley 7 , tit. xv, lib. Iv, ley dada el año 1560 .

${ }^{18}$ Acta de sesión, 8 de noviembre de 1583, $\mathrm{CHCH}$, vol. 19, 148.

"Acta de sesión, 9 de agosto 1607, снсH, vol. 24, Santiago, 1901, 52.

${ }^{18}$ Acta de sesión de 9 de septiembre de 1616, снсн, vol. 25, pp. $156,157$.
} 
dios que no tienen de que, ni pueden pagar la dicha sisa, echarles derrama"19.

El "reparto entre los vecinos de Cuyo de quince indios que serán necesarios... con acuerdò del protector de guarpes" -se trataba en esta oportunidad de la construcción del tajamar en el río Mapochoplantea de nuevo la probabilidad de que haya naturales trabajando en obras públicas como forma de pagar las derramas correspondientes a sus encomenderos 20 .

Con motivo de destructivas crecidas del ro Mapocho, el año 1620 se echó una derrama de 6.000 patacones, la que se extendió expresamente a todos los habitantes de la ciudad y de su distrito, incluidos "los indios y comunidades de repartimientos"... expresando que "no se reserve ninguno, pues a todos toca ${ }^{21}$. Ese mismo año se confirmó la provisión de 150 indios para obras públicas, concedida por el Gobernador y se dio comisión para buscarlos en la provincia de Cuyo ${ }^{22}$. En 1621 aparece noticia de la participación de los mencionados indios cuyanos en las obras del tajamar de la ciudad de Santiago. Se otorgan atribuciones especiales a Pedro Lisperguer, encargado de los trabajos, por parte del oidor decano de la Audiencia, entre las que se mencionan poner guardias cordilleranos para seguridad de los indios de Cuyo e imponer penas a quienes ocultaren indios 23 . Dichos indios trabajan con salario pagado por el Cabildo, parte del cual se les cancela en vestuario.

En el siglo xvir el trabajo en las obras públicas no aparece expresamente vinculado al repartimiento de trabajo ni éste al servicio de los indígenas de manera exclusiva como en los siglos anteriores. Esta transformación probablemente se explica como consecuencia del alto grado de mestizaje producido en la sociedad chilena, por la disminución de la población indigena, la que se traduce en la práctica en la destrucción de las reducciones indigenas y en el total empobrecimiento de las encomiendas, cuya supresión legal será a fin del siglo la mera ratificación de un hecho. Lo más probable es que ya desde la styunca nitad del siglo xvir, y tal vec antes, ni siquiera haya sido

${ }^{19}$ Acta, 30 de julio de 1616 , сHCH, vol. $25,148,149$.

-Actis, 22 de mayo de 1620, снсн, vol. 25, 397.

"Acta, 19 de noviembre de 1620, снсн, vol. 25, 894.

-Actas 24 y 29 de diciembre de 1620, СнсH, vol. 25, 424-426.

Acta de 22 de enero de 1621 . CHCH, vol. $25,453.456$. 
necesario acudir al repartimiento de trabajo para las obras públicas. La situación que nos describe el Superintendente de Obras Públicas, Manuel de Salas, respecto de la excesiva cantidad de postulantes a jornaleros en las obras públicas del Tajamar, a los que califica de "enjambre de infelices", situación que lo lleva a concluir respecto de la población laboral que "no es desidia la que domina: es la falta de ocupación la que los hace desidiosos"24, es presumible que describa una situación de tipo general, planteamiento que no parece aventurado si se consideran las conclusiones que se desprenden como rasgo común de las más recientes investigaciones sobre la estructura social chilena en el último siglo de la dominación española en la medida en que ellas se han realizado sobre documentos de aplicación del derecho y no exclusivamente sobre la legislación ${ }^{25}$.

En el siglo xvir se manifiesta otro cambio de importancia en el punto que se estudia, éste consiste en el aprovechamiento del trabajo de presidiarios en las construcciones y en la mantención de obras públicas. Con anterioridad este sistema fue utilizado al parecer en forma ocasional, en cambio en esta etapa se establece una estructura especial de los mismos presidios, destinada a hacer efectivo este empleo de la población penal. Con dicha finalidad se organizó en Santiago un segundo presidio, ubicado precisamente cerca de la construcción definitiva de los tajamares del río Mapocho, una de las obras públicas de mayor envergadura de las emprendidas en el siglo xvirr. El antiguo penal, llamado de San Pablo -el nuevo tomó su nombre de la obra en que servía- continuó con sus presidiarios adscritos al trabajo de otras obras públicas, como empedrado de calles y refacciones de puentes ${ }^{26}$.

${ }^{21}$ Escritos de Manuel de Salas y documentos relativos a él y a su familia, Santiago, 1910-1914, 3 vols. tomo I, Representación al Ministro de Hacienda sobre el estado... del Reino de Chile. 151 a 199, cita en 153.

${ }^{25} \mathrm{Me}$ refiero a estudios como los de Mario Góngora. Fernando Silva Vargas, Marcello Carmagnani o María Isabel González Pomés, en especial los siguientes: Mario Góngora, Origen de los inquilinos de Chile central. Santiago 1974; Fernando Silva Vargas, Tierras y pueblos de indios en el Reino de Chile, Santiago, 1962; Marcello Carmagnani, El salariado minero en Chile colonial, Santiago 1963; María I. González P., La encomienda indigena en Chile durante el siglo XviII, Santiago, 1966.

'Informe del Superintendente de Obras Públicas, Manual de Salas, Santiago 20 de diciembre de 1797 en: Escritos de Manuel de Salas..., tomo I, 416 a 418 . 
El puente del Mapocho, obra también muy importante, ejecutada bajo la dirección del corregidor Luis Zañartu, se habia realizado con trabajo de reos, al igual que la construcción de los refugios cordille. ranos proyectados y dirigidos pot Ambrosio Higgins a partir del año 1762 con la finalidad de mantener expedito el tránsito durante todo el año en el camino entre Santiago y Mendoza27.

c) Privilegio de expropiación y comiso o requisición de materiales y de transporte. La posibilidad de compeler a los propietarios a ven. der sus propiedades o parte de ellas si son indispensables para la ejecución de una obra pública, tasando y pagando su valor, forma en que describe Castillo de Bovadilla lo que en términos actuales llamamos expropiación por causa de utilidad pública, aparece en una larga controversia judicial producida con motivo de la construcción del camino de Santiago a Valparáso por la cuesta de Lo Prado, en el siglo xvir. Lo tardio del ejemplo allegado no significa que no puedan existir otros anteriores que yo desconozco, pero es probable que este tipo de problemas se hayan presentado a partir de una etapa de consolidación de la propiedad privada y del interés en su protección. como consecuencia del valor económico adquirido por ella.

La iniciativa de la empresa de construir otro camino entre Santiago y Valparaiso provino de la incansable actividad de don Ambrosio Higgins y a ella se unió el Cabildo de Santiago, el que decidió en sesion de 17 de mayo de 1791 , vista la utilidad y necesidad del camino, imponer un gravamen al tránsito de carretas y mulas entre la capital y el puerto. La obra se inició en septiembre del an̆o 1791 y recién comenzada se manifestó la oposición de José Miguel Prado Covarrubias, dueño de un predio afectado por el trazado hecho para la construcción de la ruta, el que recurrió a la Audiencia, tribunal en el que encontró acogida la acción pese al informe desfavorable de su fiscal. El Cabildo apoyó en forma permanente la actuación del Gobernador y tomó en esos años diversos acuerdos destinados a complementar la obra.

La controversia fue resuelta por efecto de una real orden de 4 de junio de 1793, que ratificó lo obrado por el Gobernador y dispuso por punto general, que el Presidente de Chile no otorgara apelación

Informe de Ambrosio Higgins, 29 de mayo de 1765, reproducido en el apéndice documental de: Ricardo Donoso, El marqués de Osorno don $\mathrm{Am}$. brosio Higgins, I720-1801, Santiago, 1941. Cita en 125 a 428 y 75. 
para ante la Real Audiencia en materia de caminos, dejando sólo el recurso al Rey por la vía reservada de Gracia y Justicia28.

También constituye un beneficio de las construcciones públicas el uso preferente de materiales para su edificación, privilegio que pue. de llegar al comiso o requisamiento en caso necesario. Se une a esta preferencia, la posibilidad de imponer a los particulares el transporte, generalmente remunerado, de madera, cal y demás elementos para la construcción:

El Cabildo de Santiago hizo efectivo este privilegio en favor de la construcción del puente del Maipo en 1620, disponiendo que en la ciudad y demás partes convenientes se tomara "toda la madera necesaria para la obra della y se embargue y tome, tasándola dos personas, una de la parte de la autoridad y otra del dueño ${ }^{29}$.

En la construcción de los refugios cordilleranos en el camino entre Santiago y Mendoza, a los que hemos hecho referencia con anterioridad, se hizo uso de los arrieros que atravesaban los Andes a fin de que transportaran materiales en los viajes en que no llevaban carga $^{30}$.

\section{S I S T E M A D E F I N A N C I A M I E N T O DE LAS OBRAS PUB L I C A S}

Ya sabemos que la construcción de una obra pública goza del beneficio de que su financiamiento recaiga sobre toda la población y pueda aún compremeter el erario real.

El privilegio es tan amplio que según la utilidad de una obra para obtener recursos destinados a su construcción pueden imponerse contribuciones frente a las cuales no valen las exenciones y fueros en esta materia. Así lo explica Castillo de Bovadilla ${ }^{31}$ al referirse a las atribuciones de los corregidores en estas materias, dice: "pueden echar sisa y contribución por los dichos edificios a falta de propios... en vecinos de la ciudad y tierra... por lo cual es necesaria licencia del Concejo". Agrega que se puede compeler a los hidalgos y a otros

${ }^{28}$ Los datos aqui mencionados forman parte del prolijo relato que de estos hechos hace Ricardo Donoso, ob. cit. 227 a 234.

${ }^{20}$ Acta sesión $1^{9}$ de septiemhre de I620. Снс.н. inl. 25. 384.

Informe de Ambrosio Higgins, 29 de mayo de 1765, reproducido en $R$. Donoso, ob. cit. pp. 78 y 425 a 428.

"Ob. cit. lib. iIr, cap. v, N.os 33 y 36, 80 . 
exentos seglares, a los clérigos y a otros eclesiásticos y "aún el mismo Rey, según doctrina de doctores, está obligado a contribuir".

La ley de Indias ${ }^{32}$ agrega que debe aplicarse el repartimiento a los indigenas cuando la obra les fuere útil y fuere inexcusable su contribución.

También en relación a quienes deben contribuir una ley de la Recopilación encarga a los virreyes y gobernadores determinar la necesidad de una obra pública, tasar su costo y ordenar el repartimiento "entre los que recibienen el beneficio"s3.

Respecto de la extensión territorial de las contribuciones constituidas por sisas y derramas u otras, la Recopilación de Indias dispone34 que en las cosas que fueren conveniencia pública a toda la tierra, vecinos y moradores, contribuyan y paguen todas las ciudades, villas y lugares, juntamente con la que fuere cabeza de provincia.

Por lo tanto las obras públicas se financian con tres tipos de recursos: propios o rentas del Cabildo, por insuficiencia de éstos, con arbitrios del Cabildo o sea fondos suministrados directamente por la comunidad en la forma de sisas y derramas o repartimientos u otras contribuciones especiales y por la Hacienda Real.

Revisemos el funcionamiento del sistema en Chile. Se utilizaron los propios y rentas del Cabildo de Santiago en reparaciones del puente del río Maipo, al tiempo que se comisionaba a un regidor y a] procurador de la ciudad para proveer a los gastos librando sobre los propios del Ayuntamiento. Para efectuar dichas libranzas les otorgaron "poder y comisión en forma, cual de derecho en tal caso se requiere ${ }^{35}$.

Igual financiamiento se acordó para la construcción de un puente en el potrero de la ciudad ${ }^{36}$. En 1587 se comprometen en forma genérica en beneficio de las "obras públicas", después de especificar las principales, los propios y las penas de cámara ${ }^{37}$. Debido al bajo mon. to de los propios y su consecuente incapacidad para sufragar los gastos del Cabildo, en ocasiones se crean peajes en beneficio de una obra

mec. Ind, lcy 7, tit. xy, lib. Iv.

"Rec. Ind. ley 1, tit. Xvi, lib. 1v,

HLey 2, tit. xv, lib. Iv.

5 Acta, 16 de enero de 1579, СHCH, vol. 18, 99.

Acta, 8 de noviembre de 1583, снсн, vol. 19, 148.

"Acta, 17 de julio de 1587, снсн, vol. 20. 
pública especifica o para mantención o reparación de aquella que aporta la renta. Se dan en arrendamiento previo remate al mejor postor. Hay casos en que el derecho de pasaje sobre una vía forma parte del precio entregado a un particular por la reparación de ella ${ }^{38}$.

El método más empleado para obtener recursos económicos para obras públicas fue la distribución de derramas y con menos frecuencia el cobro de sisa.

La derrama, contribución extraordinaria, fue impuesta por el Cabildo santiaguino perdiódicamente y en cada acuerdo se señalaron las obras públicas beneficiadas. Por lo general las derramas aparecen referidas, en cuanto a las personas afectadas por ellas, a los vecinos, a los moradores y a los naturales, en ocasiones con las expresiones recién mencionadas o con las de vecinos, estantes y habitantes ${ }^{39}$. En el hecho no parecen haberse considerado otras exclusiones que los eclesiásticos, iglesias, conventos y hospitales, por cuanto esta contribución se hace extensiva a esas personas y organismos en forma expresa en 1620 con ocasión de una derrama derivada de necesidades imperiosas creadas por una inundación ${ }^{40}$.

Respecto del territorio al que se extiende el cobro de una derrama, es factor determinante la utilidad general que esté destinada a prestar la obra o si dicha utilidad se reduce a un grupo de población determinado y en oportunidades se toma en cuenta el uso directo que éstos puedan realizar sobre ella. Como ilustración señalaremos los casos más esclarecedores: las obras de interés general, como es el tantas veces citado puente sobre el río Maipo, determinaron que la derrama se echara "desde el río de Maipo hasta la mar y cordillera y hasta la otra banda del Maule", lo que significa prácticamente toda la juris. dicción sur correspondiente al Cabildo metropilitano ${ }^{41}$.

Parte del término jurisdiccional norte del Cabildo quedó afectado por la derrama decretada para construir un puente sobre el río Acon-

achch, vol, 25, actas de: 11 de enero de 1620, 365; 15 de mayo de $1620,378$.

"CHCH, vol. 1, p. 111; 537 a 540.

${ }^{*}$ Acta, 13 de noviembre de 1620 , CHch, vol. 25, 394.

" $\mathrm{CHCH}$, vol. 25, 11 de septiembre de $1620, \mathrm{p}$. 388, sobre cobro de de. rrama por el Corregidor de Maule y el de Quillota; CHCH, vol. 25, 25 de reptiembre de $1620,390,391$, remate de cobro de derrama. CHCh, vol. 25 , II de diciembre de 1620, 409 a 411; chch vol. 25, 7 de abril de 1617, p. 193, "lo que faltare se reparta entre los interesados". 
cagua Se extiende la derrama al partido de Aconcagua y al de Cuyo42.

De las actuaciones del Cabildo aparecen dos formas de cobro de las derramas; por comisión o encargo del Ayuntamiento, el que recae por lo general en alguno de sus miembros o en los corregidores de los diferentes partidos. También se cobran mediante contrato con un particular previo otorgamiento de fianza por éste. Cuando el Cabildo concertaba con comisionados para el cobro de una derrama, establecía además una remuneración porcentual sobre las cantidades percibidas. Tal es el caso establecido respecto de una de las derra. mas para las obras del tajamar del Mapocho en 1619 en que se otorgó al comisionado el $5 \%$ de lo cobrado en la ciudad y el $6 \%$ "dos leguas adelante de ella"ıa. Estos porcentajes eran más elevados cuando se trataba de cobrar la contribución en otros corregimientos como es el caso de la derrama cobrada en 1620 a beneficio del puente del Maipo en que se señala $10 \%$ de la dicha cobranza, agregando el documento que esta es la cantidad pagada por tales cobranzas en otros cabildos44. En los casos en que se otorga remuneración al cobrador de la derrama se le exigen fianzas, además de la rendición de cuentas, que es obligación para todas las situaciones. Las comisiones de cobranza encargadas a los miembros del Cabildo, segín se desprende de los documentos revisados, no son remuneradas e incluso hay oportunidades en que aparecen como una imposición por la cual estas personas adquieren excepcionalmente una responsabilidad como la de responder con sus bienes por las cantidades no cobradas 45 .

Cobrada la derrama se debe entregar el dinero o especies al depositario designado por el Cabildo. En 1621 se acordó establecer anualmente un solo destinatario para todas las derramas, quien deberfa rendir fianza y cuenta de los depósitosit.

La derrama podia ser pagada en dinero o en especies de cualquier tipo cuyo precio se determinara mediante acuerdo entre el contri-

ثенсн, vol. 24, 27 de julio de 1607, p. 51: 9 de agosto de 1607, 52.

-Acta, 23 de mayo de 1619, снсH, vol. 25. 335.

“CHCH, vol. 25, 25 de septiembre de 1620, pp. 390-391: 11 de septiembre de $1620,410-411$.

\$Acla, 29 de diciembre de 1620, снсн, vol, 25, 426.

mActa, 10 de marzo de 1621, CHCH, vol. 225, 478. 
buyente y el cobrador o bien eran tasados por el Cabildo al ordenar la imposición ${ }^{47}$.

Como ejemplo del monto que alcanza una derrama podemos mencionar que para el tajamar se decretó en 1620 una contribución de seis mil patacones que debían cobrarse en el plazo de dos años. En otros casos se tasa previamente la cantidad requerida para la obra pública y esa cantidad se reparte por personas comisionadas para esa tarea específicamente 48 .

El monto de una derrama determina si se requiere o no para su imposición confirmación de la Real Audiencia. La ley indiana ${ }^{49}$ dispone que sobre quince mil maravedies hasta 200 pesos oro, se necesita autorización de la Audiencia; sobre esa cantidad se requiere autorización real. En la práctica consta el requerimiento del Cabildo para la confirmación de contribuciones por parte del organismo real $y$ en varios casos, dichas confirmaciones, pero no he comprobado el requisito de un monto mínimo para este trámite ni el alcance de éste en caso de existir 50 .

La sisa es otra de las formas que se utilizaron en Chile para financiar obras públicas. Esta contribución consistía, como sabemos, en el establecimiento de una rebaja en los pesos y medidas de artículos que se vendian para el consumo público cediendo el valor de la cantidad rebajada en beneficio del destino previsto por la ley. En 1616 se proyectó imponer una sisa sobre los cordobanes, sebo, vino y en las carretadas de leña para beneficio de las obras públicas de la fuen. te de agua de Ramón, el puente del Maipo y los tajamares, propuesta para cuya aprobación se convocó un cabildo abierto en Santiago. La contribución debía cobrarse durante cuatro años, en el territorio comprendido entre "Tinguiririca y Chuapa", esto es, la mayor parte del territorio habitado de la gobernación de Chile ${ }^{51}$.

Con la finalidad de ser invertido su producto en las tres obras pútilicas recién mencionadas, el Cabildo impuso el año 1620 , por el
plazo de tres años, una sisa que recayó sobre el vino en ventas al me-

\footnotetext{
${ }^{47}$ Acta, 11 de septiembre de 1620 , сHCH, vol. 25,410 .

${ }^{49}$ Acta, 13 de noviembre de 1620 , vol: $25,394$.

${ }^{40}$ Rec. Ind. Leyes 3, 4, cap. xv, lib. Iv.

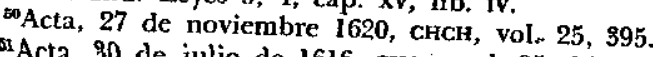

${ }^{6}$ Acta, 30 de julio de 1616, СHCH, vol. $25,148,149$.
} 
nudeo y sobre cada arroba producida en las viñas; también se cobraba sobre la entrada y salida de carretas cargadas en el puerto de Valparaíso. En este caso se mandó dar pregón para remate en el mejor postor ${ }^{52}$. Un año más tarde consta respecto de esta contribución, un Jendimiento de 286 patacones y la orden que se pregone el remate de la sisa de las carretas en $\mathbf{5 5 0}$ patacones 5 .

\section{REG I M EN DE E IECUCIÓN DE o b R A s P}

La ejecución de una obra pública iba precedida dentro del Cabildo por un acuerdo acerca de su utilidad; la iniciativa en muchos casos era llevada a la corporación por el procurador de la ciudad y rnuchas de las más, importantes tuvieron origen en decisiones de los gobernadores. El corregidor, tan importante en cuanto a las atribuciones que a este respecto le asigna la doctrina jurídica, en la realidad chilena desempeña un papel secundario frente al Cabildo, en cuyas sesiones generalmente participa y de cuyos acuerdos sobre obras públicas aparece muy seguido como un mero ejecutor. Tomada la decisión respecio de la utilidad de una obra, el Cabildo decide acerca de su financiamiento y si se requieren planos o estipulaciones de construcción, comisiona a miembros del Cabildo o al corregidor para su estudio.

Ias obras públicas se ejecutan a través de tres fórmulas distintas: por contra"o con "n particular mediante pago de un precio total por la obra; construcción directa por el Cabildo mediante comisionados y en tercer lugar, por un sistema mixto de construcción por un particular y participación del Cabildo.

Para conocex las diferentes modalidades en la ejecurción de las ohras públicas por el Cabildo, haremos uso de los documentos que aporta la construcción del puente del Maipo a través ale todo el perfodo indiano, pues una vez construido, reaparece periódic ament:s, dando origen a contratos para mantenc:ón y reparación en torno a los cuales se produccn situaciones de gran interés jurídico. También utilizaremos documentos que dan cuenta da las obras de empedrado de las calles de Santiago, por presentar similar interés.

s2Acta, 24 de enero de 1620, $\mathrm{CHCH}$, vol. 25, 967 .

*Acta, 12 de noviembre de 1621, СHch, vol. 25, 522. 
El primer contrato para construir el puente del Maipo se celebra el año 1556, y aunque en definitiva no prosperó la ejecución de la obra en la forma establecida en él, es un testimonio riquisimo y muy temprano acerca de las normas aplicadas por el Cabildo en estos casos.

Las partes contratantes están constituidas por el corregidor y por el Cabildo, parte que aparece individualizada con las expresiones: los muy magnificos señores Justicia y Regimiento de esta ciudad de Santiago del Nuevo Extremo, que están presentes por sí y en además en nombre de todos los demás vecinos y moradores... de esta ciudad" 54 : la otra parte contratante, que se obliga a la ejecución de la obra, está constituida por dos personas que se identifican con oficios de albanil uno y cantero el otro. El precio de la obra vendida o a suma alzada se concierta en seis mil pesos de "oro fundido y marcado", precio que debía pagarse en tercios; uno al comenzar el trabajo, otro en la mitad de la obra y el otro al final, sin prórroga de plazos. Se estipulan las calidades que en materia de construcción debe cumplir la obra, que en su ejecución debe ceñirse al diseño del plano que st menciona en el contrato; se deja constancia de los materiales que deben usarse, del alto, ancho y largo del puente y de sus tres arcos. En seguida las partes acuerdan ciertas modalidades del contrato, estableciendo una comisión por la cual la obligación de hacer que implica la ejecución de la obra sólo se extingue con la muerte de ambos contratantes; la obligación de dar que la convención implica pasa a los herederos según otras cláusulas. Se estipula un plazo dentro del cual los ejecutantes se obligan a "dar hecha la obra" en doce meses. Ya vimos el plazo acordado para el pago del precio y por último incluyen una cláusula penal por el incumplimiento de cualquiera de las partes, consistente en el pago del doble y costas. Convienen además en otorgar mérito ejecutivo al contrato y los constructores ex. presan una renuncia a todo fuero y a excepciones que les otorguen las leyes. Los particulares obligan al cumplimiento del contrato sus personas y todos sus bienes presentes y futuros.

La forma de ejecución aplicada por el Cabildo en el pacto que acabamos de resêñar corresponde al de una obra vendida por una suma alzada. El mismo puente del Maipo en un contrato de ejecu-

Acta, 4 de septiembre de 1556, СHCH, vol. 1, 537 a 540. 
ción similar, aunque materialmente de pretensiones más modestas, nos dará cuenta de las fórmulas empleadas para el caso de incumplímiento del contrato y para su modificación por cambio de las condiciones de ejecución.

En el afio 1579 el Cabildo determina reconstruir el puente del Maipo, pero en este caso nombra a un regidor y al procurador de la ciudad como mandatarios. Ellos deberán contratar albañiles y operarios para la obra de mano, poniendo el Ayuntamiento los materiales y el control y supervigilancia de la obra ${ }^{55}$. Se trataría del tipo de ejecución de obra pública que he llamado directa y cuya fórmula supone el nombramiento de algunos integrantes del Ayuntamicnto en calidad de comisarios, mayordomos o diputados de la obra. Estas personas reciben poder en forma y son sometidos a una fiscalización $y$ control de gastos.

En los casos de ejecución de una obra pública por intermedio de particulares, pueden presentarse problemas por incumplimiento de! contrato. En 1608, el Cabildo, ante el incumplimiento en la terminación del puente del Maipo por el constructor Pedro Miranda, acuerda poner un plazo para su entrega definitiva y para determinarlo, comisiona al alarife para que inspeccionando la obra y estado de avance de la construcción señale dicho término. Una vez fijado el término se notificó al ejecutante de la obra bajo apercibimiento de que en caso de incumplimiento dentro del nuevo término fijado. el Cabildo se haria cargo directamente de la obra a su costa ${ }^{56}$. A finales del mismo año el Cabildo ordena al constructor continuar la obra, "por haberse entregado la cal", lo que nos indica probablemen. te la interrupción del plazo por faltar los materiales 57 . Las inunda. ciones que en el año 1609 prácticamente habian destruido el puente obligan a buscar un nuevo lugar para ubicarlo, trámite que se ejecuta con el constructor Pedro Miranda a cargo del viejo puente 58 .

En 1610, ante nueva incumplimiento en el plazo de entrega del puente del Maipo por Pedro Miranda, se acuerda se le apremie en

\footnotetext{
scta, 9 de octubre de 1579, снсн, vol. 18, ed. Santiago, 1899, 139.

mActa, 8 de febrero de 1608 , СHCH, vol. 24, 75 .

${ }^{57}$ Acta, 28 de noviembre de 1608, vol. 24, CHCH, 109.

-Acta, 26 de junio de 1609, снсн, rol. 24.
} 
los mismos términos anteriores, agregando que se suspenderán los pagos ${ }^{69}$.

E1 20 de mayo de 1611 se establece un nuevo plazo, de seis meses, al mismos ejecutante de la obra, bajo apercibimiento, esta vez, de sacar a pregón la obra, debiendo aquél pagar de contado el precio del remate y ejecución sobre su persona y bienes 60 .

Transcurrido un tiempo se entabla juicio contra el constructor Pedro Miranda y su codeudor, Melchor Jufré del Aguila, por incumplimiento del plazo y defectos en la construcción de la obra. Como consecuencia de esta acción, ambos demandados son recluidos en prisión. El Cabildo dispone que una comisión del Ayuntamiento inspeccione la obra del puente e informe a la corporación para poder resolver acerca de la actitud del Cabildo frente a las defensas y excepciones presentadas por los demandados. El avenimiento en el juicio se manifiesta en una revisión de las cláusulas del contrato, acuerdo de nuevo plazo y retasación del costo de la obra, quedando en libertad los demandados ${ }^{61}$.

En ciertos casos de ejecución por particulares se remata la obra en el mejor postor. Tal es el caso de la construcción de una parte de empedrados y puentes en Santiago en el año $1746^{n 2}$. El remate se efectúa en presencia del Gobernador, Audiencia y Corregidor, habiéndose pregonado previamente las condiciones de él. Entre éstas se exigía garantizar las buenas condiciones de la obra por seis años. Se exigió fianzas y aquí también el fiador es calificado como socio en la construcción. Supervigila la obra el corregidor. El financiamiento de esta obra corrió a cargo del derecho de balanza.

En casos de ejecución mediante contrato con particulares aparece la modalidad de pago del precio con el arrendamiento dado en pú. blica subasta del cobro de un pasaie o derecho semejante.

Otra fórmula usada por el Cabildo para construir obras públicas consistió en la participación del organismo capitular en la ejecución misma proporcionando materiales, mano de obra al contratante particular, manteniendo para sí la fiscalización de la ejecución.

${ }^{50}$ Acta, 15 de octubre de 1610, CHCH, vol. 24, 201.

${ }^{\infty} \mathrm{CHCH}$, vol. $24,255$.

Año 1615, 17 de julio, chch, vol. 25, 107.

-Archivo del Cabildo de Santiago, vol. 56, libro de remates $y$ fianzas, años 1740-1746, fs. 1-3. 
A modo de conclusiones absolutamente provisorias debido a la fndole del trabajo, señalaremos dos puntos.

La actividad del Cabildo en materia de obras públicas en los siglos xvi y XvII es de gran importancia en la medida en que como institución le correspondió la mayor responsabilidad en la iniciativa, financiamiento y ejecución. Aparece secundado por el corregidor, el que se comporta en esta materia como un miembro más del Ayuntamiento.

En el siglo xvıl el Ayuntamiento sigue manteniendo una actividad semejante a la de los siglos anteriores respecto de la construcción de obras públicas; ella sin embargo adquiere un carácter secundario frente al aumento de la participación de los Gobernadores e Inten. dentes, la que es ampliamente más significativa que en los dos siglos anteriores por razones muy variadas.

Por último, cabe señalar que el régimen jurídico que el Cabildo despliega en torno a la construcción de obras públicas se maniliesta bastante creativo en relación a la normativa legal cronológicamente correspondiente, avanzando normas que aparecen más tarde en la le. gislación o continúan siendo aplicadas en la forma de una especie de estatuto jurídico consuetudinario. 